\title{
Post Traumatic Dorsal Mass of a Child Hand: Rhabdomyosarcoma Must Be Suspected
}

Randa Salem*, Asma Souri, Amina Ben Salem, Omar Toumi, Med Faouzi Hamdi, Leila Ghedira and Mondher Golli

Department of Medical Imaging, University Hospital, FB Monastir, Tunisia

\begin{abstract}
Rhabdomyosarcoma (RMS) is a highly malignant soft tissue tumor accuring in children. Strongly suggestive history of trauma is recognized as an etiological factor of RMS. rapidly growing, persistent firm, or non-mobile lesions appearing after trauma should raise the suspicion of malignancy. If doubt exists, radiological exams must be performed because appearance of RMS is highly suggestive. We report a case of 8-year-old girl with a history of trauma how's developed RMS of the dorsum of his left hand and we describe radiological appearances suggesting this diagnosis.
\end{abstract}

Keywords: Rhabdomyosarcoma (RMS); Soft tissue tumor

\section{Introduction}

Peritoneal Rhabdomyosarcoma (RMS) is the most frequent, highly malignant soft tissue tumor that develops from striated muscle cells [1]. History of trauma is recognized as an etiological factor of RMS [2]. But trauma and a small painless mass is apt to be overlooked or misdiagnosed unless the physician is constantly aware of the possibility of this possibility of malignant evolution. We report a case of 8-year-old girl with a history of trauma how's developed RMS of the dorsum of his left hand and we describe radiological appearances suggesting this diagnosis.

\section{Case Report}

An 8-year-old white child without medical history was brought for a swelling of the dorsum of her left hand. Her mother states that the mass appeared almost one year ago, few days after the girl strucked her hand when she fell, and has gradually increased in size despite a medical symptomatic care.

On physical examination, the patient weighted $20 \mathrm{~kg}$ (-3 Standard deviation), she was asthenic and has increased temperature of $38^{\circ} \mathrm{C}$.

The mass has ill-defined limits, was roughly rounded and measured $4 \mathrm{~cm} \times 5 \mathrm{~cm}$. It was firm, painful on palpation, and fixed relative to the deep plane of the dorsal $4^{\text {th }}$ and $5^{\text {th }}$ metacarpal rays.

Another painful mass was found in the inner side of the ipsilateral elbow which was $3 \mathrm{~cm}$ in long. An axillary swelling lymph node was discovered too.

Biological exams showed pancytopenia, elevated sedimentation rate, hypercalcemia and ascent of muscle enzymes.

Antéro posterior X-ray of the hand and elbow (Figure 1) revealed a soft tissue swelling over the dorsal metacarpals and an irregular erosion of the second right metacarpal. Strangely, another erosion was seen in the lower extremity of the ulna which matches with a metastatic lesion.

An ultrasound of soft tissues of the hand was performed the lesion was heterogeneous hypo echoic highly vascularized in color Doppler, surrounding the $3^{\text {rd }}$ and $4^{\text {th }}$ and $5^{\text {th }}$ metacarpals (Figure 2). At magnetic resonance imaging, the mass arouses from the dorsal and palmar interossei and occupied both the dorsal and palmar compartments of the hand. The mass was heterogeneous hyperintense to the muscles on T1WI and T2WI. Marked homogeneous enhancement was demonstrated after gadolinium injection (Figure 3).

These findings suggested a malignant soft tissue mass that most

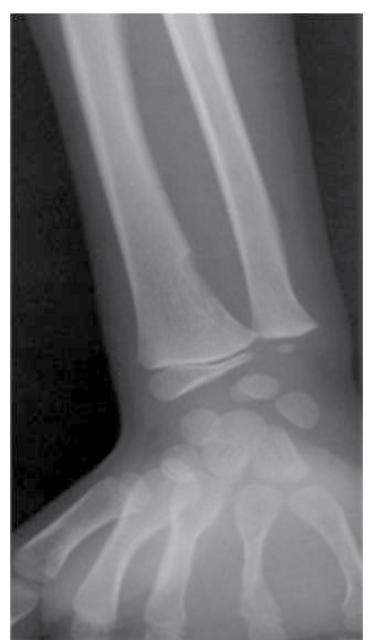

Figure 1: Antéro posterior X-ray of the right hand. Soft tissue swelling over the dorsal metacarpals and irregular erosion of the second metacarpal. Another erosion is seen in the lower extremity of the ulna.

likely originated from the interossei muscle and infiltrated the third metacarpal. Spinal MRI showed multiple vertebral collapses with heterogenous spinal matrix suggesting bone marrow involvement. Chest CT scan was performed and revealed three parenchymal metastatic nodules.

A metastatic RMS was diagnosed. Excision biopsy of the lesion was performed through a dorsal approach. The histology of the specimen was consistent with RMS showing alveolar subtype. The postoperative period was uneventful. And the patient received four intensive

*Corresponding author: Randa Salem, Department of Medical Imaging, University Hospital, FB Monastir, 5000, Tunisia, Tel: 0021695593300; E-mail: krmranda@yahoo.fr

Received: September 09, 2017; Accepted: October 24, 2017; Published: October 26, 2017

Citation: Salem R, Souri A, Salem AB, Toumi O, Hamdi MF, et al. (2017) Post Traumatic Dorsal Mass of a Child Hand: Rhabdomyosarcoma Must Be Suspected. Oncol Cancer Case Rep 3: 136.

Copyright: (C) 2017 Salem R, et al. This is an open-access article distributed under the terms of the Creative Commons Attribution License, which permits unrestricted use, distribution, and reproduction in any medium, provided the original author and source are credited. 
Citation: Salem R, Souri A, Salem AB, Toumi O, Hamdi MF, et al. (2017) Post Traumatic Dorsal Mass of a Child Hand: Rhabdomyosarcoma Must Be Suspected. Oncol Cancer Case Rep 3: 136.

Page 2 of 2
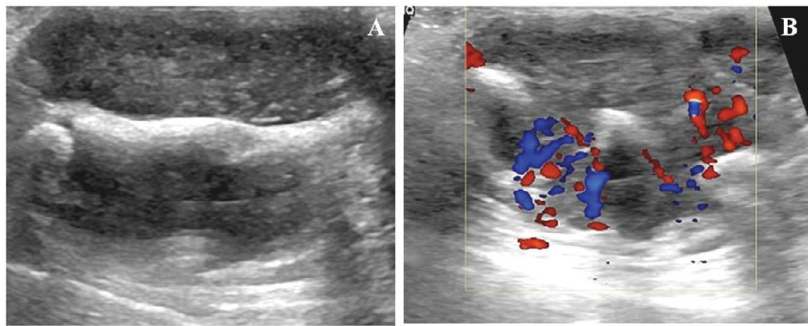

Figure 2: Longitudinal (A) and axial (B) Ultrasound of the hand showing heterogeneous hypo echoic highly vascularized lesion, surrounding the $3^{\text {rd }}$ and $4^{\text {th }}$ and $5^{\text {th }}$ metacarpals.

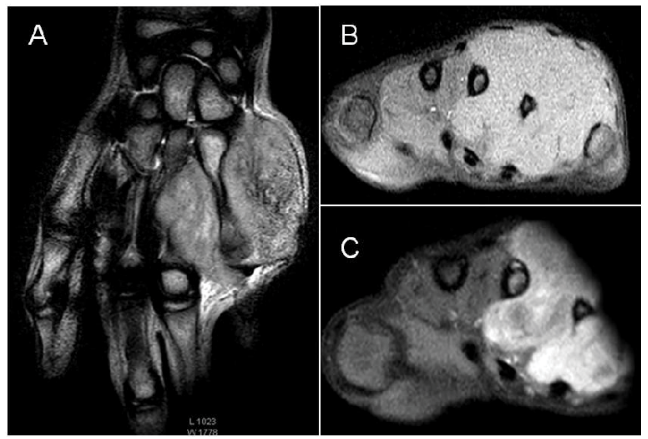

Figure 3: MRI of the right hand showing a mass arousing from the dorsal and palmar interossei and occupying both the dorsal and palmar compartments. The mass was heterogeneous hyperintense to the surrounding muscles on $\mathrm{T} 1 \mathrm{WI}(\mathrm{A})$ and $\mathrm{T} 2 \mathrm{WI}(\mathrm{B})$. After gadolinium injection the mass demonstrated marked homogeneous enhancement $(C)$.

courses of combination therapy using Vincristine, Adriamycin and Cyclophosphamide (VAC), together with radiotherapy.

\section{Discussion}

RMS is a highly malignant soft tissue tumor that develops from striated muscle cells. It accounts approximately $55 \%$ of all soft tissue sarcoma in children younger than 15 years and is more common in boys $[1,2]$. Pathogenesis of the tumor is uncertain. Strongly suggestive history of trauma is recognized as an etiological factor of RMS [3]. The trauma can occur years before the appearance of the tumor or a very short time before its recognition. In both cases, rapidly growing, persistent firm, or non-mobile lesions should raise the suspicion of malignancy [4]. Also, biological disturbance as in our described case should have drawn the attention and suggested malignancy. If doubt exists, radiological exams must be performed because appearance of RMS is highly suggestive. The couple radiography and ultrasound should be the two initial imaging studies of a suspicious hand mass as we have proceeded in our case. Plain radiographs help to differentiate a primary bone tumor from a RMS [1]. As mentioned for our girl, involvement of adjacent metacarpals by the soft tissue mass manifests as an irregular erosion of the bone [5,6]. Radiographs also allow discover some distant metastatic bone involvement like the erosion they revealed in the lower extremity of the ulna of our patient. Ultrasound offer highly sensibility detecting little calcifications described in $10 \%$ to $30 \%$ of hand RMS [1]. MRI which provides high soft tissue and spatial resolution is essential to evaluate the extent of the mass. A bone scan also should be part of the preoperative evaluation. Computerized tomography (CT) results are more informative than MRI results when evaluating cortical changes and assessing calcification within the lesion $[1,7]$. Extremity RMS is characterized by its particularly poor outcome and its high tendency to develop distant metastases. So that 5-year survival RMS of hand and limb is of $33.3 \%$ [8] and $29 \%$ of patients had distant metastases at the time of diagnosis while the usual rate for RMS of all sites is $10 \%$ to $20 \%[8,9]$. Chest CT scan should be performed to detect metastatic disease [5]. This exam showed three metastatic nodules in the case of our patient. In opposition to bone tumors, soft tissue tumors, especially RMS can metastasize to regional lymph nodes $[9,10]$. In our patient, the second painful mass of the inner side of the ipsilateral elbow corresponded surgically to a metastatic lymph node. Axillary lymph node was also resected and was metastatic. Another important characteristic is the high tendency of RMS to develop bone marrow dissemination.

\section{Conclusion}

Our reported case confirms this concept since our girl has bown marrow invasion at the time of diagnosis attested by pancytopenia, vertebral collapse and heterogenous spinal matrix on spinal MRI. In addition, even if no biological abnormality is found and because of the highest tendency of metastatic RMS to involve bone marrow, bone marrow aspiration should be a part of pretherapeutic evaluation of such children $[2,10]$. Histologically, RMS has been assigned to three histological categories: embryonal, alveolar and pleomorphic with $15 \%$ to $20 \%$ of rhabdomyosarcomas not fitting into a conventional classification and remaining either undifferentiated or unclassifiable tumors [5]. Alveolar subtype found in our case is the most frequent RMS of the extremities and has the worst prognosis [11]. Radical surgical ablation by en-bloc excision or amputation affords the best chance of survival $[2,12]$. The use of multiple agent chemotherapy regimens (for example, VAC) produced an immediate improvement in survival in patients with lesions in the extremities.

\section{References}

1. Gross E, Rao BN, Pappo AS, Michalkiewicz E, Hudson MM, et al. (1997) Soft tissue sarcoma of the hand in children: Clinical outcome and management. J Pediatric Surg 32: 698-702.

2. Salazard B, Philandrianos C (2008) Tumeurs de la main chez l'enfant. Chirurgie de la Main 27: S185-S193.

3. Potenza AD, Winslow DJ (1961) Rhabdomyosarcoma of the hand. J Bone Joint Surg 43: 700-708.

4. Ognjanovic S, Linabery AM, Charbonneau B, Ross JA (2009) Trends in childhood rhab domyosarcoma incidence and survival in the United States 1975-2005. Cancer 115: 4218-4226.

5. Xarchas K, Papavassiliou N, Tsoutseos N, Burke FD (1996)Rhabdomyosarcoma of the hand. Two case reports and a review of the literature. J Hand Surg 21: 325-329.

6. Jimenez RM1, Jaramillo D, Connolly SA (2005) Imaging of the pediatric hand Soft tissue abnormalities. Eur J Radiol 56: 344-357.

7. Navarro OM (2011) Soft tissue masses in children. Radiol Clin N Am 4: 1235-1259.

8. Shrestha A, Ritz B, Ognjanovic S, Lombardi CA, Wilhelm M, et al. (2013) Early life factors and risk of childhood rhabdomyosarcoma. Front Public Health 1: 1-8.

9. Mutz SB, Curl W (1977) Alveolar cell rhabdomyosarcoma of the hand: Case report with four-year survival and no evidence of recurrence. J Hand Surg Am 2: $283-284$.

10. Sağlık Y, Atalar H, Armangil M, Başarır K, Yıldız Y, et al. (2013) Management of tumors and tumor-like lesions of the hand: A review of 191 patients. Eklem Hastalik Cerrahisi 24: 149-155.

11. Casanova M, Meazza C, Gronchi A, Fiore M, Zaffignani E, et al. (2007) Softtissue sarcomas of the extremities in patients of pediatric age. J Child Orthop 1: 195-203.

12. La TH, Wolden SL, Su Z, Linardic C, Randall RL, et al. (2011) Local therapy for rhabdomyosarcoma of the hands and feet: Is amputation necessary? A report from the children's oncology group. Int J Radiat Oncol Biol Phys 80: 206-212. 